\title{
Y. Kitase ${ }^{\text {* }}$, S. Lee ${ }^{2}$, J. Gluhak-Heinrich ${ }^{3}$, M.L. Johnson ${ }^{1}$, S.E. Harris ${ }^{4}$, and L.F. Bonewald' \\ ${ }^{1}$ Oral and Craniofacial Sciences, School of Dentistry, University of Missouri-Kansas City, Kansas City, MO, USA; \\ CCL7 Is a Protective Factor Secreted by Mechanically Loaded Osteocytes
} ${ }^{2}$ Endocrinology, Internal Medicine, Eulji University School of Medicine, Daejeon City, Republic of Korea; ${ }^{3}$ Orthodontics; and ${ }^{4}$ Periodontics and Cellular and Structural Biology, University of Texas Health Science Center at San Antonio, San Antonio, TX, USA; *corresponding author, kitasey@ umkc.edu

J Dent Res 93(1 1):1108-1115, 2014

\begin{abstract}
In a search for factors up-regulated by mechanical strain in osteocytes, we discovered that chemokine (C-C motif) ligand 7 (CCL7), a chemotactic myokine, was highly expressed in MLO-Y4 osteocytelike cells. Although MLO-Y4 cells secrete potent chemotactic factors for osteoclast precursors, CCL7 was not responsible for this activity. CCL7 was increased in osteocytes in response to tooth movement in vivo. Since mechanical loading plays a crucial role in maintaining osteocyte viability, CCL7 was tested for protective activity and found to be protective against cell death induced by dexamethasone and etoposide. CCL7 specific antibody partially, but in combination with indomethacin, completely abrogated the protective effects of fluid flow shear stress against dexamethasone-induced cell death. CCL 7 activated the $\beta$-catenin pathway through phosphorylation of glycogen synthase kinase 3 (GSK-3), suggesting that this pathway is responsible for the observed protective effects. A related cytokine, CCL2, also produced by MLO-Y4 cells but not regulated by mechanical loading, proved to be more potent and protected against cell death induced by not only dexamethasone, but also by Tumor Necrosis Factor $\alpha(\mathrm{TNF} \alpha)$. Whereas osteocytes may produce CCL2 in constitutively low levels, a major function of mechanically induced CCL7 may be to selectively protect osteocytes in an autocrine manner against glucocorticoid-induced cell death.
\end{abstract}

KEY WORDS: cell death, mechanical stress, chemokine, tooth movement, glucocorticoid, TNF $\alpha$.

\section{DOI: $10.1177 / 0022034514553008$}

Received June 10, 2014; Last revision September 3, 2014; Accepted September 5, 2014

A supplemental appendix to this article is published electronically only at http://jdr.sagepub.com/supplemental.

(C) International \& American Associations for Dental Research

\section{INTRODUCTION}

O steocytes, which are terminally differentiated osteoblasts embedded in the mineralized matrix, compose $90-95 \%$ of all bone cells (Frost, 1960; Parfitt, 1977). Osteocytes regulate mineral homeostasis both locally and systematically (Feng et al., 2006; Liu et al., 2006) and orchestrate osteoblast and osteoclast activity in response to mechanical stimuli to regulate bone formation and resorption (Li et al., 2008; Nakashima et al., 2011). Osteocyte cell death is associated with age and pathological conditions and may be responsible for increased fragility due to loss of capacity to sense microdamage necessary for initiation of bone repair (Manolagas, 2000). Osteocyte viability therefore plays a significant role in the maintenance of bone homeostasis and integrity. Mechanical loading plays a role in maintaining osteocyte viability. Shear stress generated within the osteocyte lacuna-canalicular system by bone fluid is thought to be the form of mechanical loading to which the osteocyte is most likely exposed. Fluid flow shear stress (FFSS) inhibits osteocyte apoptosis induced by serum starvation (Bakker et al., 2004) and by dexamethasone (dex) (Kitase et al., 2010).

In a search for osteocyte factors that could respond to FFSS and recruit osteoclast precursors to target bone for resorption (see Appendix Tables 1 and 2), we identified one of the chemokines, CCL7, also known as monocyte chemotactic protein-3, MCP-3, produced by the osteocyte cell line murine long bone osteocyte Y4, MLO-Y4. Even though MLO-Y4 conditioned medium is chemotactic for osteoclast precursors, this activity could not be blocked by CCL7 specific antibody, suggesting the possibility of another function of CCL7 in osteocytes. Chemokines were first described based upon their capacity to stimulate recruitment of leukocytes to sites of inflammation and later to function as protective factors in many types of cells, including bone cells (Okamatsu et al., 2004; Wright et al., 2005; Yano et al., 2005). This raised the possibility that CCL7 could be a protective factor for osteocytes.

This study was performed to determine whether CCL7 could be a factor secreted by osteocytes in response to FFSS, responsible for mediating the protective effect of FFSS on glucocorticoid-induced osteocyte cell death. Previously, we had shown that prostaglandin E2 $\left(\mathrm{PGE}_{2}\right)$ produced by osteocytes in response to FFSS is a protective factor by activating the $\beta$-catenin pathway (Kitase et al., 2010). Here we show that CCL7 is highly expressed in osteocyte-like MLO-Y4 cells and up-regulated by mechanical loading in vitro and in vivo. CCL7 selectively rescues osteocyte cell death induced by dex but not by the inflammatory cytokine, Tumor Necrosis Factor, TNF $\alpha$. The 
protective effect of FFSS is partially mediated by CCL7 but also through prostaglandin production and activation of the $\beta$-catenin signaling pathway.

\section{MATERIALS \& METHODS \\ Cell Culture}

MLO-Y4 osteocyte-like cells were cultured on collagen type I-coated plates (rat tail collagen type I, $0.15 \mathrm{mg} / \mathrm{mL}$ ) in alpha minimum essential medium ( $\alpha$-MEM) supplemented with $2.5 \%$ fetal bovine serum, $2.5 \%$ bovine calf serum in a $5 \% \mathrm{CO}_{2}$ incubator at $37^{\circ} \mathrm{C}$. Both $2 \mathrm{~T} 3$ and MC3T3-E1 osteoblast-like cells were cultured in $\alpha$-MEM supplemented with $10 \%$ FBS.

\section{Quantitative Real-time Polymerase Chain-reaction (PCR)}

Taqman real-time quantitative PCR analysis was performed as previously described (Kitase et al., 2010). Relative expression levels were obtained by the $\triangle \triangle \mathrm{Ct}$ method. GAPDH expression levels were used for normalization.

\section{Enzyme-linked Immunosorbent Assay (ELISA)}

MLO-Y4 cells were incubated in 48-well plates at $1 \times 10^{4}$ cells/ $0.3 \mathrm{~mL}$ medium/well in the presence or absence of $1 \mu \mathrm{M}$ dex for 24 and $48 \mathrm{hr}$. After treatment, soluble CCL7 was quantitated with a commercially available kit according to manufacturer's protocols (Bender Medsystems, Vienna, Austria). The values are expressed as fold increase after normalization with cell number.

\section{Northern Blot Analysis}

MLO-Y 4 cells were exposed to $2 \mathrm{hr}$ of FFSS at 16 dynes $/ \mathrm{cm}^{2}$. After FFSS, the cells were incubated for $30 \mathrm{~min}$ and $24 \mathrm{hr}$. Northern blot analysis was performed as described previously (Chen et al., 1998) with a mouse $1 \mathrm{~kb}$ CCL7 complementary (c)DNA probe.

\section{Tooth Movement and in situ Hybridization}

All animal procedures were performed in compliance with the regulations and guidelines of the Animal Care Committee of The University of Texas Health Science Center at San Antonio. Three-month-old C57BL6 mice were anesthetized, and an opening coil spring was bonded directly to the right incisor and maxillary first molar as described previously (Pavlin et al., 2000). A continuous force (10-12 g) was applied for $24 \mathrm{hr}$. The left side served as a control for each mouse. The maxillary complex was dissected, fixed, decalcified, dehydrated through methanol, embedded in paraffin, and sectioned at 7- $\mu \mathrm{m}$ thickness. The sections were processed for in situ hybridization with mouse ribonucleic acid (RNA) probes labeled with ${ }^{32} \mathrm{P}-\mathrm{rUTP}$ as previously described (Pavlin et al., 2000).

\section{Quantification of Cell Death}

MLO-Y4 cells stably transfected with nuclear green fluorescent protein (GFP) were plated at $1 \times 10^{4} / \mathrm{cm}^{2}$ on a collagen-coated 48-well plate with 3-4 wells for each experimental condition. MC3T3-E1 cells were plated at $4 \times 10^{4} / \mathrm{cm}^{2}$. Cells were pre- treated with recombinant murine CCL7, CCL2 (R\&D Systems, Minneapolis, MN, USA) and/or CD40L (Amgen, Thousand Oaks, CA, USA) for $30 \mathrm{~min}$, followed by treatment with $1 \mu \mathrm{M}$ dex, $50 \mu \mathrm{M}$ etoposide (Sigma-Aldrich, St. Louis, MO, USA), or $1 \mathrm{ng} / \mathrm{mL}$ TNF $\alpha$ (R\&D Systems) for $6 \mathrm{hr}$. CD40L was used as positive control, because it was previously shown to inhibit apoptosis of MLO-Y4 cells induced by the above three apoptotic agents (Ahuja et al., 2003). In this assay, phenol red free $\alpha$-MEM (Invitrogen, Carlsbad, CA, USA) was used for both MLO-Y4 and MC-3T3-E1 cells.

\section{The Nuclear Fragmentation Assay}

MLO-Y4 cells exhibiting chromatin condensation and nuclear fragmentation were detected by fluorescence microscopy. Five hundred cells were examined for each experimental condition by systematic random sampling. Digital images were acquired with an optronics camera and analysis imager software.

\section{The Trypan Blue Exclusion Assay}

After treatment, adherent cells were released by trypsin-ethylenediaminetetraacetic acid (EDTA), combined with floating cells, and pelleted by centrifugation. Then, $0.04 \%$ trypan blue (Sigma-Aldrich) was added, and cells exhibiting both nuclear and cytoplasmic staining were determined by means of a hemocytometer under a light microscope. One hundred cells per experimental condition were counted. The percentage of MLOY4 cells stained with trypan blue has previously been shown to correlate with that of apoptotic cells (Plotkin et al., 1999).

\section{Western Blot Analysis}

MLO-Y4 cells were incubated with $100 \mathrm{ng} / \mathrm{mL}$ CCL7 with or without pre-incubation with wortmannin for $30 \mathrm{~min}$. After treatment, the cells were processed for Western blot analysis according to previously described methods (Kitase et al., 2010) with the primary antibodies anti-phospho-GSK-3 $\alpha / \beta(1: 1,000, \mathrm{R} \& \mathrm{D}$ Systems) and anti-GSK- $3 \alpha$ and $\beta$ (1:1,000, Cell Signaling Technology, Danvers, MA, USA).

\section{Immunofluorescence Staining for Detection of $\beta$-catenin}

MLO-Y4 cells were treated with $100 \mathrm{ng} / \mathrm{mL}$ CCL7 for $1 \mathrm{hr}$. After treatment, immunofluorescence was performed as previously described (Kitase et al., 2010). The primary antibody against $\beta$-catenin (E-17) (1:100, Santa Cruz Biotechnology, Inc., Santa Cruz, CA, USA) was used.

\section{Microarray Analysis and Osteoclast Precursor Chemotaxis Assay}

Methods for these experiments are listed in the Appendix.

\section{Statistical Analysis}

Data are expressed as means $\pm \mathrm{SD}$. The statistical significance of difference between mean values was determined by one-way ANOVA followed by Tukey-Kramer post hoc analysis except in Fig. 3C, which was done by simple-effect one-way ANOVA. $P<.05$ was considered significant. 


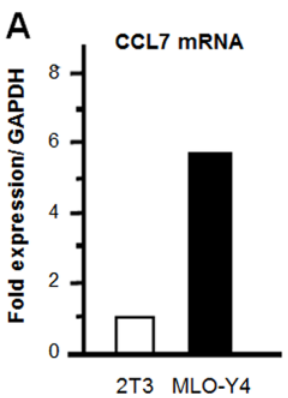

$\mathbf{B}$

\begin{tabular}{lcc}
\hline GENE SYMBOL & $\mathbf{3 0} \mathbf{~} \mathbf{m}$ & $\mathbf{2 4} \mathbf{h}$ \\
\hline CCL7 (Scya7) & 3.5 & 2.0 \\
CCL2 (Scya2) & $\mathrm{NC}$ & $\mathrm{NC}$ \\
CCR1 & 7.3 & 2.5 \\
CCR2 & 2.1 & 0.4 \\
\hline
\end{tabular}

C
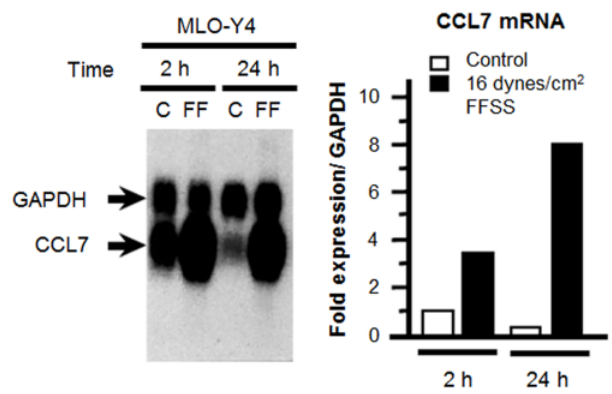

D

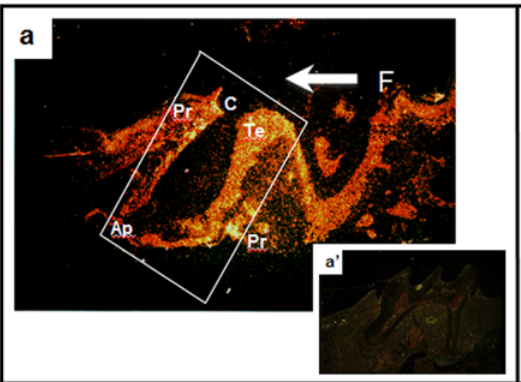

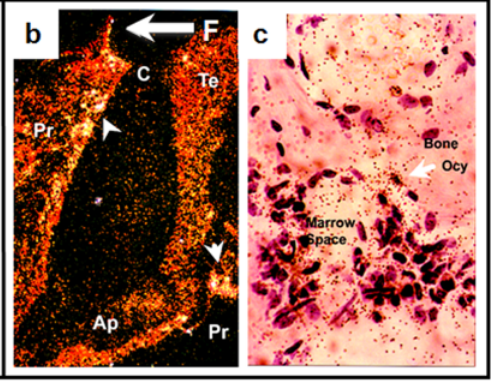

Figure 1. MLO-Y4 osteocyte-like cells express large amounts of CCL7, which is regulated by fluid flow shear stress. (A) Quantitative real-time PCR (left) and ELISA (right) showing CCL7 gene and protein expression in MLO-Y4 cells compared with 2T3 cells. (B) Results taken from gene array analysis (the dataset will be submitted to the GEO Data Base Repository, http://www.ncbi.nlm.nih.gov/geo/) showing the expression levels of CCL7, CCL2, and their receptors at $30 \mathrm{~min}$ and $24 \mathrm{hr}$ after cessation of 16 dynes $/ \mathrm{cm}^{2} \mathrm{FFSS}$. The expression levels of chemokines and receptors are shown as fold expression based on expression levels in non-treated MLO-Y4 cells at 30 min and $24 \mathrm{hr}$, respectively. NC, not changed. (C) Northern blot analysis showing CCL7 mRNA expression in MLO-Y4 cells at 2 and $24 \mathrm{hr}$ after exposure to $16 \mathrm{dynes} / \mathrm{cm}^{2} \mathrm{FFSS}$ for $2 \mathrm{hr}$. The expression level of CCL7 is shown as fold change based on the expression level in non-treated MLO-Y4 cells at 2 hr. (D) CCL7 is up-regulated in osteocytes in pressure areas during tooth movement. Tissue was harvested at $24 \mathrm{hr}$ after loading of the maxillary first molar and processed for in situ hybridization as described in "Materials \& Methods". This Fig. shows a representative section in dark (a, a', and b) and bright (c) fields. (a) Dark-field view of the first molar. Strong hybridization signals are seen on the pressure side in both the alveolar bone and the periodontal ligament. (a') Control. (b) A higher magnification of the large box in Fig. 1Da. Arrowheads point toward strong positive signals of CCL7 in individual periodontal ligament cells (upper) and osteocytes (lower). (c) Bright-field view at high magnification of the small box in Fig. 1Da. An arrow points to late osteoblasts-early osteocytes showing intense hybridization with the CCL7 probe. Full arrows = direction of orthodontic force; $\mathrm{Pr}$, periodontal site under compressive stress; Te, periodontal site under tensile stress; $C$, coronal region of the root; $A P$, root apex; arrowheads = differential hybridization signals for CCL7; Ocy, late osteoblasts-early osteocytes.

\section{RESULTS}

\section{MLO-Y4 Osteocyte-like Cells Express Large Amounts of CCL7, Which Is Regulated by Fluid Flow Shear Stress, FFSS}

Since CCL7 was found to be highly expressed in MLO-Y4 osteocyte-like cells compared with osteoblast-like $2 \mathrm{~T} 3$ cells by gene array analysis (see Appendix Table 1), the amounts and regulation by mechanical stimuli both in vitro and in vivo were investigated. CCL7 messenger (m)RNA was six-fold higher in MLO-Y4 cells than 2T3 cells as determined by real-time PCR (Fig. 1A, left). By ELISA, MLO-Y4 cells cultured for $24 \mathrm{hr}$ produced four-fold higher amounts of CCL7 protein than 2T3 cells (Fig. 1A, right). From gene array analysis (Fig. 1B), CCL7 mRNA was increased by FFSS three- to four-fold at $30 \mathrm{~min}$ and maintained for $24 \mathrm{hr}$ after cessation of FFSS. CCL2, which shares receptors with CCL7 (Rollins, 1997), was elevated in MLO-Y4 cells compared with 2T3 cells (see Appendix Table 1), but not increased in response to FFSS (Fig. 1B). CCR1, a receptor for CCL7, was up-regulated 7.3-fold $30 \mathrm{~min}$ after cessation of FFSS and sustained at the 2.5 -fold level $24 \mathrm{hr}$ after FFSS.
CCR2, a receptor for both CCL7 and CCL2, was increased twofold at the same time-point and reduced by $24 \mathrm{hr}$. Northern blot analysis confirmed that FFSS increased CCL7 mRNA 3.5-fold at $2 \mathrm{hr}$ and 16-fold at $24 \mathrm{hr}$ after cessation of FFSS (Fig. 1C). This suggests the potential for autocrine effects of CCL7, especially in response to FFSS.

\section{CCL7 Is Up-regulated in Osteocytes in Pressure Areas during Tooth Movement}

The tooth movement model is ideal for examining gene expression in cells, since both resorption and formation occur simultaneously. The application of force in the coronal region causes a tipping tooth movement, resulting in compressive stress $(\mathrm{Pr})$ in the coronal portion of the mesial periodontium and in the apical portion of the distal periodontium in the distal root. Fig. 1D shows a dark-field view of the maxillary first molar. Strong hybridization signals were observed in both the alveolar bone and periodontal ligament on the pressure side. Regions under pressure showed a strong differential signal, while the tension region showed a uniform, non-specific hybridization signal (Figs. 1Da, 1Db). Fig. 1Dc shows late osteoblasts-early 
osteocytes (Ocy) on the pressure side with strong positive signals for CCL7. This is consistent with in vivo microarray data (Paic et al., 2009), which shows that both mature osteoblasts (Col2.3 $\mathrm{cyan}^{+}$) and pre-osteocytes/osteocytes $\left(\right.$ DMP1topaz $\left.{ }^{+}\right)$express CCL7 with the average intensity of 2139 and 797, respectively.

\section{CCL7 Significantly Inhibits Cell Death of MLO-Y4 and MC3T3-E 1 Cells Induced by Dexamethasone, Dex}

Even though CCL7 is highly expressed in osteocytes and regulated by mechanical stimuli both in vitro and in vivo, antibody to CCL7 could not block the chemotactic activity of MLO-Y4 cells on MOPC-5 cells, nor did addition of CCL7 protein have any effect (see Appendix Table 2). Since FFSS has a protective effect on osteocyte viability (Kitase et al., 2010), we hypothesized that CCL7 may function as a protective factor. CCL7 prevented dex-induced cell death in a dose-dependent manner, as determined by both nuclear fragmentation and trypan blue exclusion (Fig. 2A). CCL7 also inhibits dex-induced cell death in osteoblast MC3T3-E1 cells (Appendix Table 3).

\section{CCL7 Partially Mediates the Protective Effects of Fluid Flow Shear Stress on Dex-induced Cell Death}

Antibody to CCL7 (1 $\mu \mathrm{g} / \mathrm{mL})$ significantly but not completely reduced the protective effects of FFSS (16 dynes/ $\mathrm{cm}^{2}$ ) on dex-induced cell death (Fig. 2B, left). Control IgG had no effect. However, the combination of anti-CCL7 antibody $(1 \mu \mathrm{g} / \mathrm{mL})$ and indomethacin (100 nM) completely abrogated the protective effects of FFSS (Fig. 2B, right). The combination of indomethacin and control IgG had a partial effect.

\section{CCL7 Selectively Rescues MLO-Y4 Cell Death Induced by Dexamethasone and Etoposide, but Not by TNF $\alpha$, Whereas CCL2 Potently Blocks Cell Death Due to Dex and TNF $\alpha$}

CCL7, $100 \mathrm{ng} / \mathrm{mL}\left(\cong 1 \times 10^{-8} \mathrm{M}\right)$, protects against etoposide similar to dex (Fig. 3A); however, it failed to prevent TNF $\alpha$ -

A

B
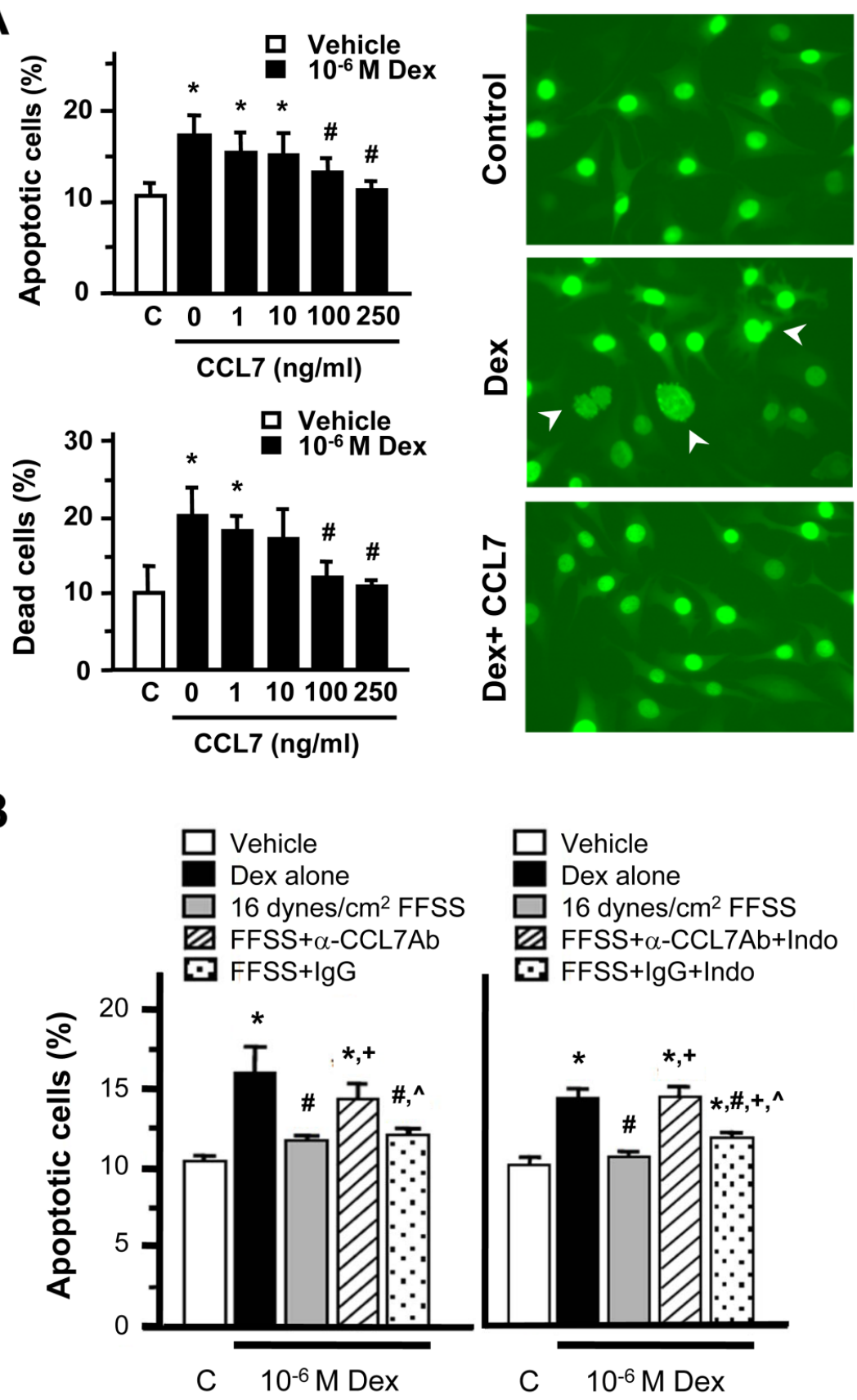

Figure 2. CCL7 blocks dex-induced cell death in MLO-Y4 cells and is partially responsible for the protective effects of fluid flow shear stress. (A) Nuclear fragmentation (upper) and trypan blue exclusion (lower) data showing significant blocking effects of CCL7 at 100 and $250 \mathrm{ng} /$ $\mathrm{mL}$ on dex-induced cell death. Representative images of nuclear fragmentation of MLO-Y4 cells with each treatment are shown on the right. ${ }^{*} p<.05$ vs. control. \#p $<.05$ vs. pro-apoptotic agent alone. (B) Effects of FFSS, $\alpha$-CCL7Ab, and lgG on dex-induced cell death (left). Effects of FFSS, $\alpha$-CCL7Ab, lgG, and indomethacin on dex-induced cell death (right). ${ }^{*} p<.05 v s$. control. \#p<.05 vs. dex alone. $+p<.05$ vs. dex+FFSS. ${ }^{\wedge} p<.05$ vs. dex + FFSS $+\alpha-C C L 7 A b$ (left) or dex+FFSS $+\alpha-C C L 7 A b+$ indomethacin (right).

induced cell death (Fig. 3B). Even when the CCL7 concentration was increased to $1 \mu \mathrm{g} / \mathrm{mL}\left(\cong 1 \times 10^{-7} \mathrm{M}\right), 20$ times greater than the concentration sufficient to significantly inhibit dex-induced cell death, no significant effect on TNF $\alpha$-induced cell death was observed. Like CCL7, CCL2 can inhibit dex-induced cell death, 

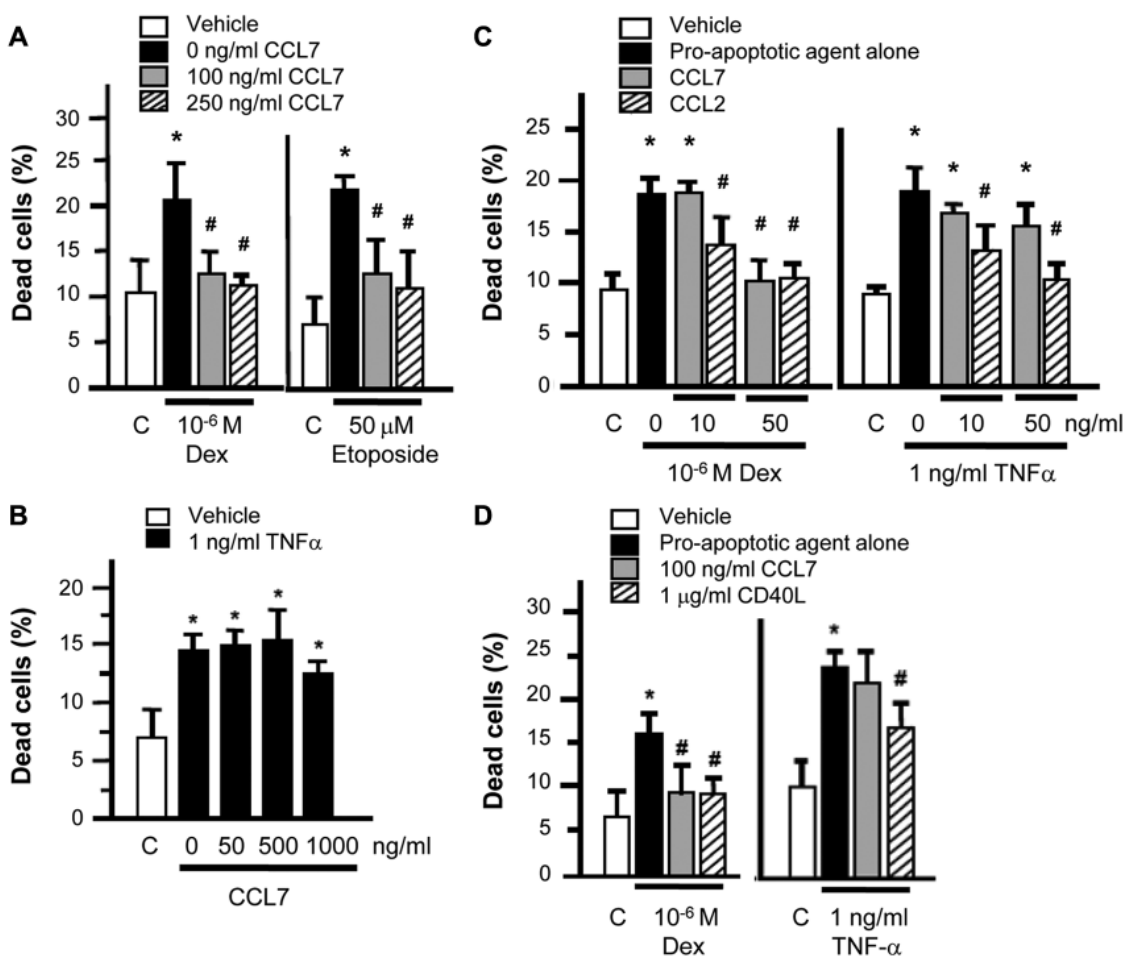

Figure 3. $\mathrm{CCL} 7$ blocks cell death due to etoposide as well as dex, but not to TNF $\alpha$, whereas CCL2 and CD4OL block the effects of TNF $\alpha$. (A) Effects of 100 and $250 \mathrm{ng} / \mathrm{mL}$ of CCL7 on cell death induced by $50 \mu \mathrm{M}$ etoposide as compared with dex. (B) No effect of CCL7 up to $1,000 \mathrm{ng} / \mathrm{mL}$ was observed against $1 \mathrm{ng} / \mathrm{mL}$ TNF $\alpha$-induced cell death. (C) CCL2 is more potent than $\mathrm{CCL} 7$ in blocking both dex- and TNF $\alpha$-induced cell death. ${ }^{*} p<.05$ vs. control. $\# p<.05$ vs. pro-apoptotic agent alone. (D) CD4OL protects against dex-induced cell death similar to CCL7, but unlike CCL7, and like CCL2 protects against TNF $\alpha$-induced cell death. ${ }^{*} p<.05$ vs. control. \#p <.05 vs. pro-apoptotic agent alone.

but at a lower dose $\left(10 \mathrm{ng} / \mathrm{mL} \cong 1 \times 10^{-9} \mathrm{M}\right)$. Unlike CCL7, CCL2 inhibited TNF $\alpha$-induced cell death at a concentration of $10 \mathrm{ng} / \mathrm{mL}$ $\left(\cong 1 \times 10^{-9} \mathrm{M}\right)$ (Fig. 3C). Next, the potency of CCL7 was compared with that of $\mathrm{CD} 40 \mathrm{~L}$, which was previously shown to prevent apoptosis of MLO-Y4 cells and osteoblast-like MC3T3-E1 cells (Ahuja et al., 2003). Fig. 3D shows that CCL7 can prevent MLO-Y4 cell death induced by dex at a six-fold lower amount $\left(100 \mathrm{ng} / \mathrm{mL} \cong 1 \times 10^{-8} \mathrm{M}\right)$ than CD40L $\left(1 \mu \mathrm{g} / \mathrm{mL} \cong 6 \times 10^{-8} \mathrm{M}\right)$. However, like CCL2, CD40L will block TNFo-induced cell death, although at a much higher amount (Fig. 4D). Therefore, these three agents show similar activities, but distinct differences in potencies and target specificity.

\section{CCL7 Activates the $\beta$-catenin Pathway}

We have previously shown that the $\beta$-catenin pathway is responsible for the protective effects of FFSS, prostaglandin, and muscle-secreted factors against osteocyte/osteoblast cell death (Kitase et al., 2010; Jähn et al., 2012). To determine if CCL7 also utilizes this pathway, we performed Western blot analysis for GSK3 phosphorylation and nuclear translocation of $\beta$-catenin. CCL7 was able to increase the phosphorylation of both GSK-3 $\alpha$ and GSK$3 \beta$ isoforms approximately two- to three-fold compared with the control (Fig. 4A). To determine if the PI3K/Akt pathway is responsible for the phosphorylation of GSK-3 induced by CCL7, we used a PI3K inhibitor, wortmannin. Wortmannin inhibited the phosphorylation of GSK-3 induced by CCL7 (Fig. 4A). In addition, immunofluorescent staining with a specific antibody to $\beta$-catenin showed that CCL7 promoted nuclear translocation of $\beta$-catenin, as indicated by the bright nuclear staining (Fig. 4B).

\section{Dex Inhibits the Expression of CCL7 and CCL2 in MLO-Y4 Cells}

By gene array analysis (Fig. 4C), dex suppressed CCL7 mRNA levels approximately three- to four-fold. Dex also inhibited other chemokines such as CCL2, but had no effect on CCR1 and CCR2. Real-time PCR analysis also validated that the expression of CCL7 mRNA in MLO-Y4 cells was 3 4 times lower compared with that in each untreated control (Fig. 4D, left). ELISA was performed to determine the effects of dex on CCL7 protein expression in MLO-Y4 cells (Fig. 4D, right). Dex significantly inhibited the expression level of CCL7 approximately two- to three-fold compared with each control.

\section{DISCUSSION}

In this study, a novel function for the chemokine CCL7 in osteocytes is described: that of an autocrine, mechanically regulated agent that provides protection against glucocorticoid-induced cell death. The chemokine CCL2 is also produced by osteocytes, but at lower levels, is not mechanically regulated but is more potent and is effective against TNF $\alpha$-induced cell death. Therefore, the osteocyte may have several mechanisms for maintaining viability against numerous apoptotic agents under different conditions.

The expression and function of chemokines and their receptors in bone have been reported mainly in osteoblast and osteoclast lineage cells (Ota et al., 2013; Shahnazari et al., 2013; Wintges et al., 2013; Govey et al., 2014). Analysis of recent emerging data shows that chemokines produced by osteocytes may regulate bone homeostasis (Chen et al., 2010; Hoshino et al., 2013; Leucht et al., 2013). In the present study, mechanical stimulation was shown to increase expression of CCL7 in MLO-Y4 cells within hours after the application of FFSS. By in situ hybridization, CCL7 increased in osteocytes as well as in late osteoblasts near the pressure side of alveolar bone in the tooth movement model. The CCL7 receptors, CCR1 and CCR2, were also elevated in MLO-Y4 cells and increased by FFSS. These findings suggest that CCL7 in response to mechanical loading may act in an autocrine and paracrine fashion to maintain osteocyte function and viability. 
A
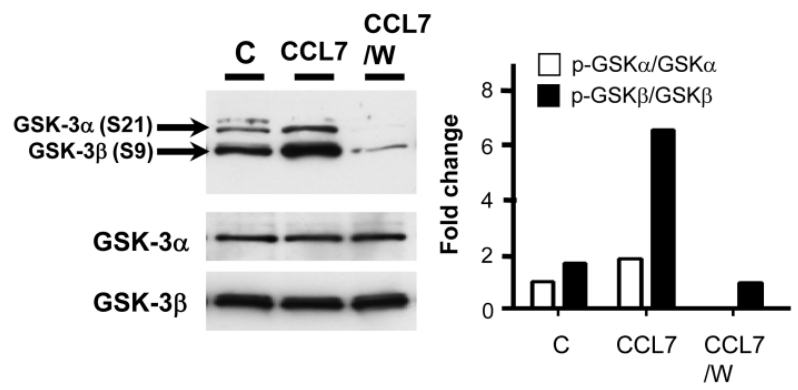

B

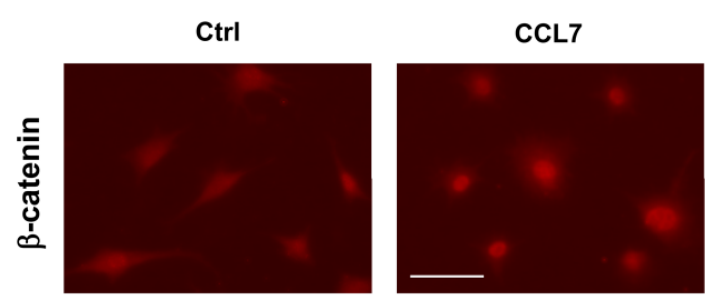

C

\begin{tabular}{lcc}
\hline GENE SYMBOL & $\mathbf{4 ~ h}$ & $\mathbf{2 4} \mathbf{~ h}$ \\
\hline CCL7 (Scya7) & $\mathbf{0 . 3 8}$ & $\mathbf{0 . 2 1}$ \\
CCL2 (Scya2) & $\mathbf{0 . 4 5}$ & $\mathbf{0 . 3 0}$ \\
CCL5 (Scya5) & 0.73 & 0.30 \\
CCL9 (Scya9) & 0.76 & 0.53 \\
CCR1 & $\mathrm{NC}$ & $\mathrm{NC}$ \\
CCR2 & $\mathrm{NC}$ & $\mathrm{NC}$ \\
BMP7 & $\mathrm{NC}$ & $\mathrm{NC}$ \\
Gilz (Tsc22d3) & 15.81 & 7.27 \\
Fkbp51 (Fkbp5) & 3.88 & 5.97 \\
\hline
\end{tabular}

D

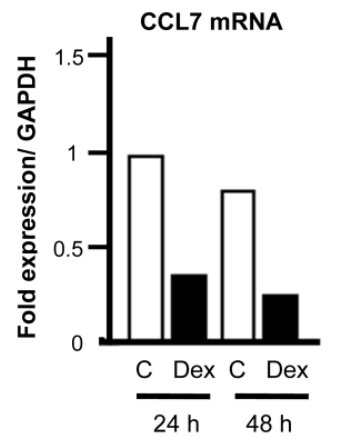

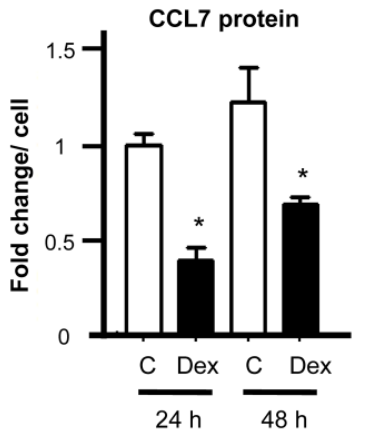

Figure 4. The effects of $\mathrm{CCL7}$ are mediated through the $\beta$-catenin pathway. Dex inhibits the expression of the protective factors CCL7 and CCL2 in MLO-Y4 cells. (A) The effects of CCL7 appear to be mediated through the $\beta$-catenin pathway. Western blot analysis showing phosphorylation

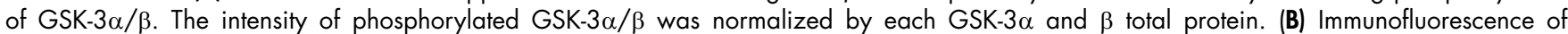
$\beta$-catenin showing nuclear translocation with CCL7 treatment. (C) Results taken from a gene array analysis (Kitase et al., 2010 ; the dataset will be submitted to the GEO Data Base Repository, http://www.ncbi.nlm.nih.gov/geo// showing the expression levels of chemokines, their receptors, and BMP7 at 4 and $24 \mathrm{hr}$ of dex exposure. Expression levels are described as fold change based on expression levels in non-treated MLO-Y4 cells at 4 and $24 \mathrm{hr}$, respectively. Genes positively regulated by dex, Gilz, and Fkbp51 are also shown. NC, not changed. (D) Quantitative realtime PCR (left) and ELISA (right) showing CCL7 expression in MLO-Y4 cells at 24 and $48 \mathrm{hr}$ of dex exposure. ${ }^{*} p<.05$ vs. each control.

Glucocorticoid treatment is the primary therapy for many inflammatory and autoimmune diseases, but it is well-known to cause the adverse effect of secondary osteoporosis. Increased osteocyte apoptosis is thought to be responsible for increased skeletal fragility and fracture risk due to reduced capacity to sense and repair microdamage (Tomkinson et al., 1997; Weinstein et al., 1998, 2000; O'Brien et al., 2004). Long-term use of corticosteroids has been reported to have adverse effects on oral and craniofacial bones such as the mandible (Beeraka et al., 2013). Osteocyte viability is therefore thought to be essential in maintaining bone homeostasis and integrity (Manolagas, 2000). Mechanical loading at physiological levels is wellknown to maintain osteocyte viability, while pathological loading results in osteocyte cell death (Verborgt et al., 2000; Noble et al., 2003; Bakker et al., 2004; Aguirre et al., 2006; Mann et al., 2006). Previous studies showed that chemokines can elicit protective effects against apoptosis in many cell types, including bone cells (Okamatsu et al., 2004; Wright et al., 2005; Yano et al., 2005). We therefore examined whether CCL7 can protect osteocytes against glucocorticoid-induced cell death.

The present study clearly shows that CCL7 is very potent at protecting both osteocytes and osteoblasts from dex-induced cell death, comparable with previously reported protective agents (see Appendix Table 4), but not from cell death induced by TNF $\alpha$, which is involved in postmenopausal primary osteoporosis (Tomkinson et al., 1997; Teitelbaum, 2004), in contrast to CCL2 and other protective agents. Parathyroid hormone (PTH) has been shown to have selective ability as a protective factor similar to CCL7 (Jilka et al., 1999), indicating that both PTH and CCL7 may inhibit cell death through similar mechanisms. This has implications for the treatment of primary and secondary osteoporosis.

How this selectivity is achieved is not clear, but could be due to differences between glucocorticoid- and cytokine-specific receptors and their death signaling pathways. Clearly, glucocorticoid functions through a classic nuclear receptor and membrane signaling to regulate target genes responsible for apoptosis induction (Schmidt et al., 2004; Gu et al., 2005) and involves disruption of mitochondria permeability, followed by release of cytochrome $\mathrm{C}$ and subsequent activation of caspase 9 , which initiates the apoptosis cascade (Yoshino et al., 2001). $\mathrm{TNF} \alpha$ induces apoptosis through direct ligation of the death receptor, TNFR1, followed by activation of caspase 8 , resulting in initiation of the caspase cascade and amplification through 
mitochondria (Thorburn, 2004). This suggests that the magnitude of TNF $\alpha$-induced cell death might be much greater than that of glucocorticoid-induced cell death. The protective effects of chemokines are reported to be associated with regulation of the BCL-2 protein family, which functions within mitochondrial membranes (Boehme et al., 2000; Li et al., 2003; Tarzami et al., 2005). Therefore, the survival signals induced by CCL 7 and CCL2 might be more potent against glucocorticoid-induced cell death, which is initiated by mitochondrial disruption.

CCL2 shares the same CCR2 receptor with CCL7 and in the present study significantly rescued cell death mediated by TNF $\alpha$. CCL2 was also more potent with respect to inhibiting dex-induced cell death compared with CCL7 $(10 \mathrm{ng} / \mathrm{mL} \cong 1 \times$ $\left.10^{-9} \mathrm{M} v s .50 \mathrm{ng} / \mathrm{mL} \cong 5 \times 10^{-9} \mathrm{M}\right)$. The different potencies of CCL 7 and CCL2 may be due to their different binding affinities for CCR2 (Kurihara and Bravo, 1996), the promiscuous nature of chemokines in binding to other receptors, or heterogeneity due to glycosylation and/or amino terminal processing. This may explain the functional disparity between CCL7 and CCL2. Further investigation will be required to understand the mechanism responsible for the selective protective effect of CCL7.

Osteocyte viability is crucial for bone homeostasis. To maintain osteocyte viability, protective factors are produced systematically and locally. Recently, we identified prostaglandin as an osteocyte autocrine, early-protective factor induced by mechanical loading within minutes (Kitase et al., 2010). Analysis of the data presented here suggests that CCL7 is a late-protective factor elevated within a few hours of load similar to BMP7, recently described as a protective factor (Wang and Guo, 2013). The PI3K/Akt/GSK-3/ $\beta$-catenin pathway has been shown to play a critical role in maintaining osteocyte viability in response to mechanical stimuli (Kitase et al., 2010; Wang and Guo, 2013). As with prostaglandin and BMP7, CCL7 appears to be protective through activation of the $\beta$-catenin pathway. Interestingly, gene array analysis showed that dex inhibits the expression of osteocyte protective factors CCL7, CCL2, Cox-1 and -2 (enzymes for prostaglandin synthesis), but not BMP7. Analysis of the present data therefore suggests that mechanical loading may have the capacity to increase osteocyte viability factors to prevent osteocyte cell death, thereby maintaining the integrity of bone.

\section{ACKNOWLEDGMENTS}

This work was supported by the National Institutes of Health (NIH)/National Institute of Arthritis and Musculoskeletal and Skin Diseases (NIAMS), grant PO1 AR046798 to S.E.H. and L.F.B. The authors declare no potential conflicts of interest with respect to the authorship and/or publication of this article.

\section{REFERENCES}

Aguirre JI1, Plotkin LI, Stewart SA, Weinstein RS, Parfitt AM, Manolagas $\mathrm{SC}$, et al. (2006). Osteocyte apoptosis is induced by weightlessness in mice and precedes osteoclast recruitment and bone loss. J Bone Miner Res 21:605-615.

Ahuja SS, Zhao S, Bellido T, Plotkin LI, Jimenez F, Bonewald LF (2003). CD40 ligand blocks apoptosis induced by tumor necrosis factor alpha, glucocorticoids, and etoposide in osteoblasts and the osteocyte-like cell line murine long bone osteocyte-Y4. Endocrinology 144:1761-1769.

Bakker A, Klein-Nulend J, Burger E (2004). Shear stress inhibits while disuse promotes osteocyte apoptosis. Biochem Biophys Res Commun 320:1163-1168.

Beeraka SS, Natarajan K, Patil R, Manne RK, Prathi VS, Kolaparthi VS (2013). Clinical and radiological assessment of effects of long-term corticosteroid therapy on oral health. Dent Res J (Isfahan) 10:666-673.

Boehme SA, Lio FM, Maciejewski-Lenoir D, Bacon KB, Conlon PJ (2000).

The chemokine fractalkine inhibits Fas-mediated cell death of brain microglia. J Immunol 165:397-403.

Chen D, Ji X, Harris MA, Feng JQ, Karsenty G, Celeste AJ, et al. (1998). Differential roles for bone morphogenetic protein (BMP) receptor type IB and IA in differentiation and specification of mesenchymal precursor cells to osteoblast and adipocyte lineages. J Cell Biol 142:295-305.

Chen W, Qing H, He Y, Wang J, Zhu Z, Wang H (2010). Gene expression patterns of osteocyte-like MLO-Y4 cells in response to cyclic compressive force stimulation. Cell Biol Int 34:425-432.

Feng JQ, Ward LM, Liu S, Lu Y, Xie Y, Yuan B, et al. (2006). Loss of DMP1 causes rickets and osteomalacia and identifies a role for osteocytes in mineral metabolism. Nat Genet 38:1310-1315.

Frost HM (1960). Measurement of osteocytes per unit volume and volume components of osteocytes and canaliculae in man. Henry Ford Hosp Med Bull 8:208-211.

Govey PM, Jacobs JM, Tilton SC, Loiselle AE, Zhang Y, Freeman WM, et al. (2014). Integrative transcriptomic and proteomic analysis of osteocytic cells exposed to fluid flow reveals novel mechano-sensitive signaling pathways. $J$ Biomech 47:1838-1845.

Gu G, Hentunen TA, Nars M, Härkönen PL, Väänänen HK (2005). Estrogen protects primary osteocytes against glucocorticoid-induced apoptosis. Apoptosis 10:583-595.

Hoshino A, Ueha S, Hanada S, Imai T, Ito M, Yamamoto K, et al. (2013). Roles of chemokine receptor CX3CR1 in maintaining murine bone homeostasis through the regulation of both osteoblasts and osteoclasts. $J$ Cell Sci 126(Pt 4):1032-1045.

Jähn K, Lara-Castillo N, Brotto L, Mo CL, Johnson ML, Brotto M, et al. (2012). Skeletal muscle sectreted factors prevent glucocorticoidinduced osteocyte apoptosis through activation of $\beta$-catenin. Eur Cell Mater 24:197-209.

Jilka RL, Weinstein RS, Bellido T, Roberson P, Parfitt AM, Manolagas SC (1999). Increased bone formation by prevention of osteoblast apoptosis with parathyroid hormone. J Clin Invest 104:439-446.

Kitase Y, Barragan L, Qing H, Kondoh S, Jiang JX, Johnson ML, et al. (2010). Mechanical induction of PGE2 in osteocytes blocks glucocorticoid-induced apoptosis through both the beta-catenin and PKA pathways. J Bone Miner Res 25:2657-2668.

Kurihara T, Bravo R (1996). Cloning and functional expression of mCCR2, a murine receptor for the C-C chemokines JE and FIC. J Biol Chem 271:11603-11607.

Leucht P, Temiyasathit S, Russell A, Arguello JF, Jacobs CR, Helms JA, et al. (2013). CXCR4 antagonism attenuates load-induced periosteal bone formation in mice. J Orthop Res 31:1828-1838.

Li A, Dubey S, Varney ML, Dave BJ, Singh RK (2003). IL-8 directly enhanced endothelial cell survival, proliferation, and matrix metalloproteinases production and regulated angiogenesis. J Immunol 170:3369-3376.

Li X, Ominsky MS, Niu QT, Sun N, Daugherty B, D'Agostin D, et al. (2008). Targeted deletion of the sclerostin gene in mice results in increased bone formation and bone strength. J Bone Miner Res 23:860-869.

Liu S, Zhou J, Tang W, Jiang X, Rowe DW, Quarles LD (2006). Pathogenic role of Fgf23 in Hyp mice. Am J Physiol Endocrinol Metab 291:E38-E49.

Mann V, Huber C, Kogianni G, Jones D, Noble B (2006). The influence of mechanical stimulation on osteocyte apoptosis and bone viability in human trabecular bone. J Musculoskelet Neuronal Interact 6:408-417.

Manolagas SC (2000). Birth and death of bone cells: basic regulatory mechanisms and implications for the pathogenesis and treatment of osteoporosis. Endocr Rev 21:115-137.

Nakashima T, Hayashi M, Fukunaga T, Kurata K, Oh-Hora M, Feng JQ, et al. (2011). Evidence for osteocyte regulation of bone homeostasis through RANKL expression. Nat Med 17:1231-1234. 
Noble BS, Peet N, Stevens HY, Brabbs A, Mosley JR, Reilly GC, et al. (2003). Mechanical loading: biphasic osteocyte survival and targeting of osteoclasts for bone destruction in rat cortical bone. Am J Physiol Cell Physiol 284:C934-C943.

O’Brien CA, Jia D, Plotkin LI, Bellido T, Powers CC, Stewart SA, et al. (2004). Glucocorticoids act directly on osteoblasts and osteocytes to induce their apoptosis and reduce bone formation and strength. Endocrinology 145:1835-1841.

Okamatsu Y, Kim D, Battaglino R, Sasaki H, Spate U, Stashenko P (2004). MIP-1 gamma promotes receptor-activator-of-NF-kappa-Bligand-induced osteoclast formation and survival. J Immunol 173:2084-2090.

Ota K, Quint P, Weivoda MM, Ruan M, Pederson L, Westendorf JJ, et al. (2013). Transforming growth factor beta 1 induces CXCL16 and leukemia inhibitory factor expression in osteoclasts to modulate migration of osteoblast progenitors. Bone 57:68-75.

Paic F, Igwe JC, Nori R, Kronenberg MS, Franceschetti T, Harrington P, et al. (2009). Identification of differentially expressed genes between osteoblasts and osteocytes. Bone 45:682-692.

Parfitt AM (1977). The cellular basis of bone turnover and bone loss: a rebuttal of the osteocytic resorption-bone flow theory. Clin Orthop Relat Res 127:236-247.

Pavlin D, Goldman ES, Gluhak-Heinrich J, Magness M, Zadro R (2000). Orthodontically stressed periodontium of transgenic mouse as a model for studying mechanical response in bone: the effect on the number of osteoblasts. Clin Orthod Res 3:55-66.

Plotkin LI, Weinstein RS, Parfitt AM, Roberson PK, Manolagas SC, Bellido $T$ (1999). Prevention of osteocyte and osteoblast apoptosis by bisphosphonates and calcitonin. J Clin Invest 104:1363-1374.

Rollins BJ (1997). Chemokines. Blood 90:909-928.

Schmidt S, Rainer J, Ploner C, Presul E, Riml S, Kofler R (2004). Glucocorticoid-induced apoptosis and glucocorticoid resistance: molecular mechanisms and clinical relevance. Cell Death Differ 11(Suppl 1):S45-S55.

Shahnazari M, Chu V, Wronski TJ, Nissenson RA, Halloran BP (2013). CXCL12/CXCR4 signaling in the osteoblast regulates the mesenchymal stem cell and osteoclast lineage populations. FASEB J 27:3505-3513.

Tarzami ST, Calderon TM, Deguzman A, Lopez L, Kitsis RN, Berman JW (2005). MCP-1/CCL2 protects cardiac myocytes from hypoxia-induced apoptosis by a G(alphai)-independent pathway. Biochem Biophys Res Commun 335:1008-1016.

Teitelbaum SL (2004). Postmenopausal osteoporosis, T cells, and immune dysfunction. Proc Natl Acad Sci USA 101:16711-16712.

Thorburn A (2004). Death receptor-induced cell killing. Cell Signal 16:139144.

Tomkinson A, Reeve J, Shaw RW, Noble BS (1997). The death of osteocytes via apoptosis accompanies estrogen withdrawal in human bone. $J$ Clin Endocrinol Metab 82:3128-3135.

Verborgt O, Gibson GJ, Schaffler MB (2000). Loss of osteocyte integrity in association with microdamage and bone remodeling after fatigue in vivo. J Bone Miner Res 15:60-67.

Wang Z, Guo J (2013). Mechanical induction of BMP-7 in osteocyte blocks glucocorticoid-induced apoptosis through PI3K/AKT/GSK3 $\beta$ pathway. Cell Biochem Biophys 67:567-574.

Weinstein RS, Jilka RL, Parfitt AM, Manolagas SC (1998). Inhibition of osteoblastogenesis and promotion of apoptosis of osteoblasts and osteocytes by glucocorticoids. Potential mechanisms of their deleterious effects on bone. J Clin Invest 102:274-282.

Weinstein RS, Nicholas RW, Manolagas SC (2000). Apoptosis of osteocytes in glucocorticoid-induced osteonecrosis of the hip. $J$ Clin Endocrinol Metab 85:2907-2912.

Wintges K1, Beil FT, Albers J, Jeschke A, Schweizer M, Claass B, et al. (2013). Impaired bone formation and increased osteoclastogenesis in mice lacking chemokine (C-C motif) ligand 5 (Ccl5). J Bone Miner Res 28:2070-2080.

Wright LM, Maloney W, Yu X, Kindle L, Collin-Osdoby P, Osdoby P (2005). Stromal cell-derived factor-1 binding to its chemokine receptor CXCR4 on precursor cells promotes the chemotactic recruitment, development and survival of human osteoclasts. Bone 36:840-853.

Yano S, Mentaverri R, Kanuparthi D, Bandyopadhyay S, Rivera A, Brown EM, et al. (2005). Functional expression of beta-chemokine receptors in osteoblasts: role of regulated upon activation, normal $\mathrm{T}$ cell expressed and secreted (RANTES) in osteoblasts and regulation of its secretion by osteoblasts and osteoclasts. Endocrinology 146:2324-2335.

Yoshino T, Kishi H, Nagata T, Tsukada K, Saito S, Muraguchi A (2001). Differential involvement of p38 MAP kinase pathway and Bax translocation in the mitochondria-mediated cell death in TCR- and dexamethasone-stimulated thymocytes. Eur J Immunol 31:2702-2708. 